\title{
Parametric study of electrochemical discharge drilling on ceramic material using Taguchi method
}

Pravin PAWAR, Amaresh KUMAR, Raj BALLAV

DOI: 10.30464/jmee.2018.2.3.193

Cite this article as:

Pawar P., Kumar A., Ballav R. Parametric study of electrochemical discharge drilling on ceramic material using

Taguchi method. Journal of Mechanical and Energy Engineering, Vol. 2(42), No. 3, 2018, pp. 193-200.

VOLUME 2(42) | No. 3 | SEPTEMBER 2018 ISSN 2544-0780 | e-ISSN 2544-1671

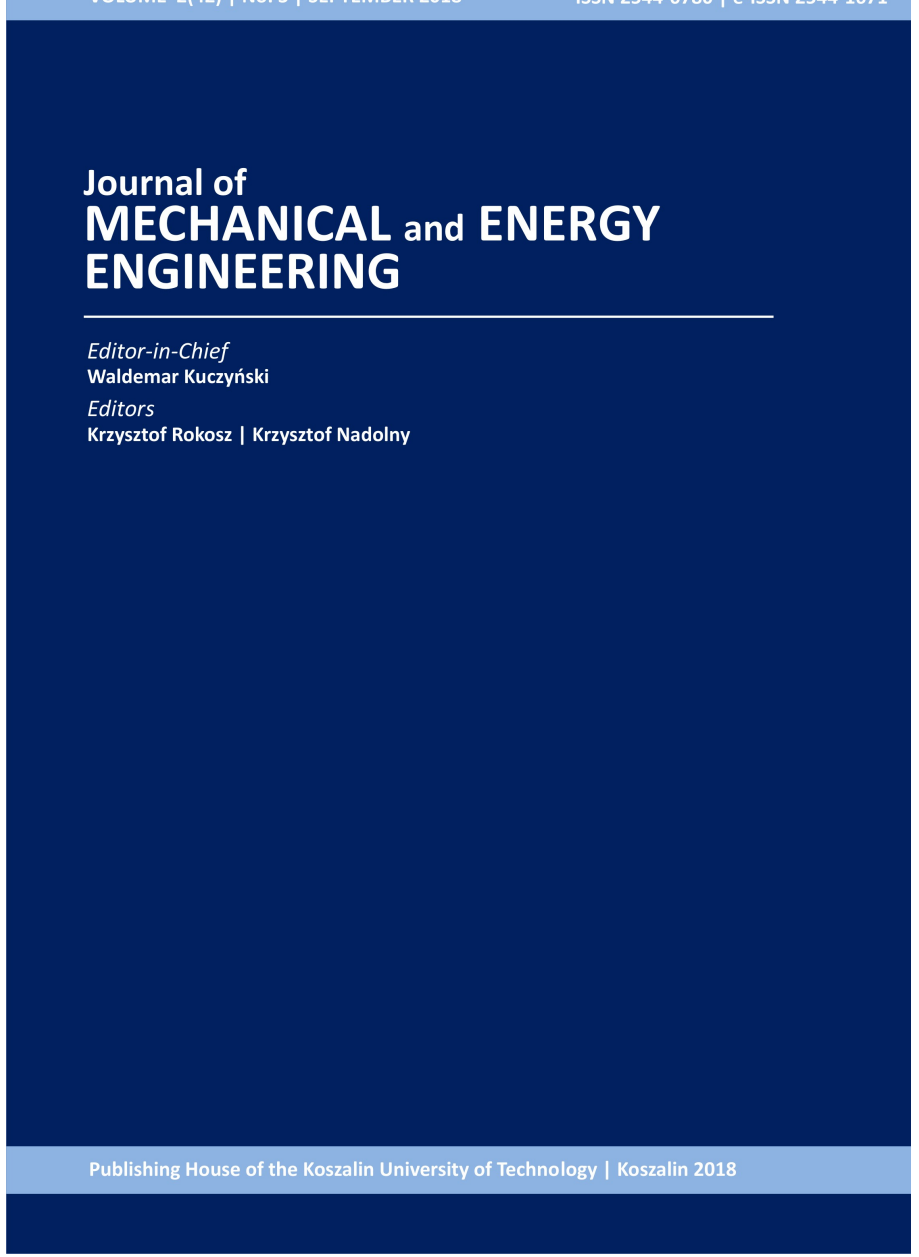

Journal of Mechanical and Energy

Engineering

Website: jmee.tu.koszalin.pl

ISSN (Print): 2544-0780

ISSN (Online): 2544-1671

Volume: 2(42)

Number: 3

Year: 2018

Pages: $193-200$

Article Info:

Received 10 August 2018

Accepted 10 September 2018

\section{Open Access}

This article is distributed under the terms of the Creative Commons Attribution 4.0 (CC BY 4.0) International License (http://creativecommons.org/licenses/by/4.0/), which permits unrestricted use, distribution, and reproduction in any medium, provided you give appropriate credit to the original author(s) and the source, provide a link to the Creative Commons license, and indicate if changes were made. 


\title{
PARAMETRIC STUDY OF ELECTROCHEMICAL DISCHARGE DRILLING ON CERAMIC MATERIAL USING TAGUCHI METHOD
}

\author{
Pravin PAWAR ${ }^{1 *}$, Amaresh KUMAR ${ }^{2}$, Raj BALLAV ${ }^{2}$ \\ 1* Department of Manufacturing Engineering, National Institute of Technology, Jamshedpur, India, 831014, \\ e-mail:pravin.1900@gmail.com \\ ${ }^{2}$ Department of Manufacturing Engineering, National Institute of Technology, Jamshedpur, India, 831014
}

(Received 10 August 2018, Accepted 10 September 2018)

\begin{abstract}
The Electrochemical Discharge machining (ECDM) is a hybrid machining technology which is combined with electro discharge machining and electro chemical machining process. In this research, electrochemical discharge drilling operation is carried out on conventional ceramic tile by using a designed and manufactured ECDM setup. The experiments were performed as per design of experimental technique of Taguchi $\mathrm{L}_{27}$ orthogonal array using MINITAB 17 software. The important process parameters that have been selected are voltage, rotation and electrolyte concentration with output response as machining depth and diametric cut. From the observations, it is found that the voltage is the most significant parameter for the machining depth and diametric cut followed by electrolyte concentration and rotation.
\end{abstract}

Keywords: diametric cut, electrochemical discharge drilling, machining depth, ceramic, Taguchi

\section{INTRODUCTION}

The materials of composites and ceramics can be machined with a combination of advanced conventional and non-conventional manufacturing processes. These machining processes create changes in size, shape, and surface finish to get a high-quality product [1]. The electrochemical discharge machining (ECDM) process firstly introduced in the year 1968 by Kurafuji through attempting micro drilling on glass material [2]. The ECDM technology is a combination of two machining processes which include the electro discharge machining process (EDM) and the electrochemical machining (ECM) process. The erosion of material is taking place because of two phenomena, i.e. electrochemical dissolution of the material and thermal erosion of electrical discharges that take place between the anode and cathode tool electrodes [3]. The ECDM technology can be excellently utilized for the machining of nonconductive materials like ceramics, glass and advanced composites. In this process, the spark discharge exploits across the gas bubble layers produced on the workpiece surface, and therefore, erosion of material takes place [4]. The ECDM process is also called as spark assisted chemical engraving process and electrochemical spark machining process. The process can be effectively used in the field of MEMS interfacing, microfactories, and micro fluidic devices [5]. In this machining technology, researchers have commonly utilized $\mathrm{NaOH}$ as an electrolyte chemical solution, Tungsten carbide as a cathode tool electrode material and Graphite as an anode tool electrode material [6]. The voltage is an utmost key factor for material removal rate then the electrolyte concentration is secondary significant parameter and last is inter electrode gap [7]. The gas film is vital for ECDM process, but the stability and dynamics of this film conditions are also important during the machining process [8]. The deeper hole drilling is achieved and controlled by the hydrodynamic regime; however, the speed of drilling is limited by the flow of electrolyte inside the microhole [9]. The machined hole circularity increases due to rotation of tool electrode, but it is not dominant factor like voltage [10]. The voltage is most significant factor for radial overcut during ECDM micro drilling 
operation [11]. The material removal rate and machined depth were enhanced due to abrasive tool electrodes in the electrochemical spark abrasive drilling process [12]. Likewise, the rotary abrasive tool electrode has improved cutting and machining ability due to the presence of abrasive grains in the drilling actions on A12O3 material [13]. The flat sidewall-flat front tool in the ECDM micro drilling process enhances the machining accuracy. As well as, the rotational rate of the tool has improved the process performance [14]. The change in tool rotational speed has minute influence on the ECDM process parameters. Also, gas film formation time drops and tends to be a minimum by rise in voltage [15]. The voltage, inter electrode gap and electrolyte concentration were the dominant factors in consequence on output responses of radial overcut and material removal rate [16]. The $\mathrm{KOH}$ electrolyte produces higher bubbles than $\mathrm{H} 2 \mathrm{SO} 4$ electrolyte solution therefore it gives higher material removal rate. [17]. The finite element method explicit dynamics ANSYS was used for analysis of different material in electrochemical discharge machine structure [18]. Similarly, Goud et al. analysed material removal rate in electrochemical discharge machining using a threedimensional finite element method [19]

Previously, Pawar et al. investigated material removal rate and tool wear rate during machining of ceramic material and he also investigated material removal rate of soda-lime glass material [20, 21]. In this paper, the investigated diametric cut and machining depth during drilling on ceramic material by using the ECDM process with the same input data of Pawar et al. So, this paper is a continuation of previously carried out experimental works.

\subsection{Basic Mechanism of ECDM}

The ECDM process shown in Fig. 1 a high voltage DC power supply was used for the machining process, and aqueous solution of hydroxides was utilized as electrolyte in ECDM cell. In this process, voltage was increased in the range of $0-12 \mathrm{~V}$.

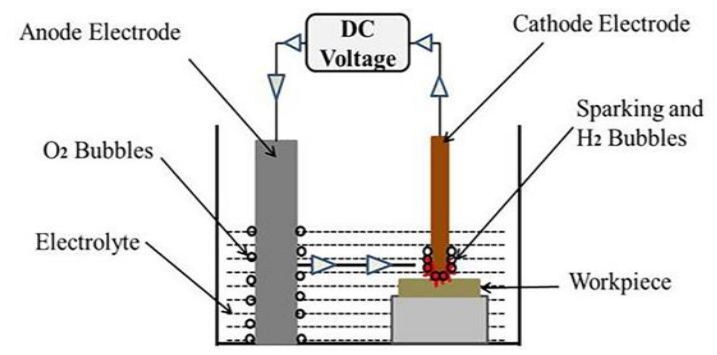

Fig. 1. Basic mechanism of ECDM process

The electrolysis with gas bubbles is formed at the electrode around surfaces. At the stage of higher voltage, a maximum critical current value take place. This is because of high intensity of hydrogen bubbles produced at the cathode being coalesced to generate a film on tool. Then, with further rise in voltage, the current fell down to a lower value due to film creation of gas bubbles. Finally, increase in voltage causes breaking of gas film to produce spark because of high intensity flow of electrons from cathode to electrolyte [22].

\section{EXPERIMETNAL SETUP AND EXPERIMENTAL PROCEDURE}

The ECDM schematic diagram and machine setup was designed and developed which is presented in Figure 2 and Figure 3.

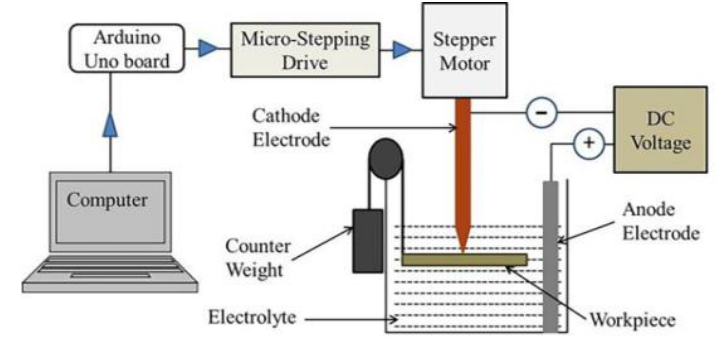

Fig. 2. Schematic diagram of ECDM setup

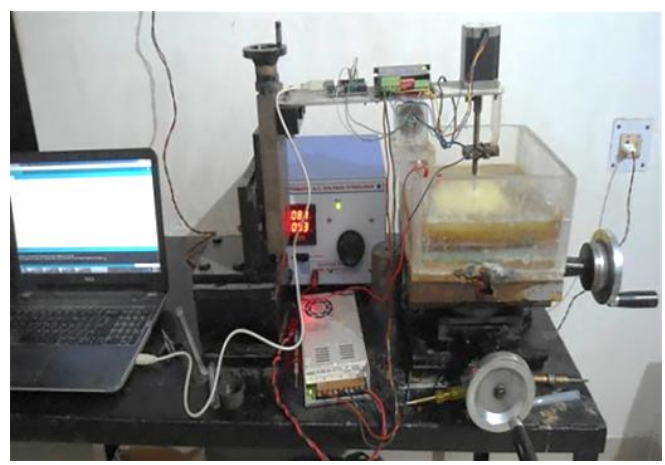

Fig. 3. Fabricated experimental ECDM setup

This machine is fabricated by using $2 \mathrm{D}$ drawings and 3D model [23]. The experimental setup of ECDM consists of $\mathrm{X}-\mathrm{Y}$ stage for manual movement on the base platform which was used to move the workpiece. The workpiece was fixed on a holding fixture. The gravity loaded mechanism was used for the movement of the workpiece from lower to upper $\mathrm{Z}$ axis movement. A rectangular tank made up of acrylic material was used as ECDM cell which contains $\mathrm{NaOH}$ electrolyte solution, cathode and anode tool electrodes. The single axis slide system was used as $\mathrm{Z}$ axis movement which was fixed to the table. The NEMA 23 stepper motor was attached to the flat beam which was attached to the top position of a single axis slide system. The cathode tool electrode attached to spindle of stepper motor, and this motor was connected to micro-stepping drive. This microstepping drive was connected to Arduino Uno board, and Arudino Uno board was connected to computer. The rotating movement of cathode tool electrode was controlled by using Arduino software programming 
through computer and $\mathrm{Z}$ axis movement from cathode tool to workpiece was operated manually.

The gravity feeding mechanism was applied to the workpiece which moved upwards to cathode electrode tool tip point. The regulated DC voltage source was used to supply DC voltage between cathode tool electrode and an auxiliary tool electrode. The stainless steel 416 rod was used as an anode electrode which was put into an electrolyte container. Figure 4 shows spark generation during micro drilling of conventional ceramic in ECDM process.

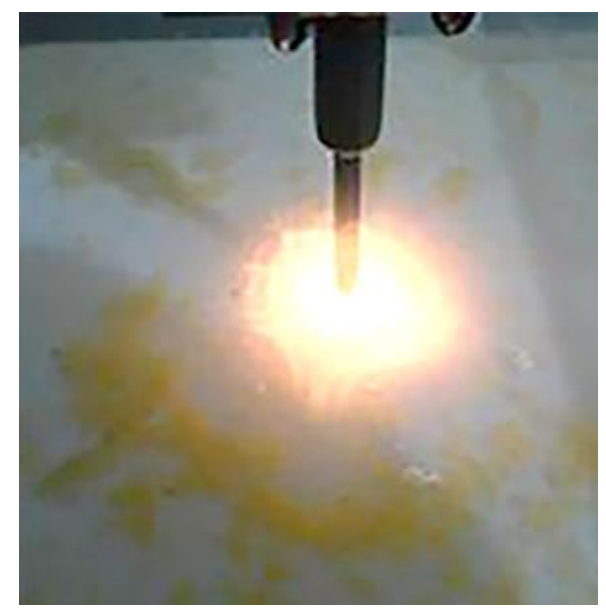

Fig. 4. Sparking during ECDM drilling on ceramic

\subsection{Experimental Conditions}

The experiments were carried out based on Taguchi $\mathrm{L}_{27}$ orthogonal array with process parameters as voltage, rotation and electrolyte concentration which are varied in three levels shown in Table 1 . The machining depth and diametric cut are taken as output responses. The machining depth and diametric cut was measured by using digital Vernier caliper. The experiments were performed with $150 \times 125 \times 8 \mathrm{~mm}^{3}$ conventional ceramic tile as workpiece material and using conical shaped $3 \mathrm{~mm}$ diameter brass cathode tool electrode. The starting point tool diameter was $1 \mathrm{~mm}$ and its diameter increased up to $3 \mathrm{~mm}$ due to conical shape given to the tool electrode. The conical shape length of $5 \mathrm{~mm}$. The experimental work was conducted on a fabricated electrochemical discharge machine. The $\mathrm{NaOH}$ was used as an electrolyte medium. The machining time was set to be 25 minutes for each experiment. The inter electrode gap between the cathode and anode tool was kept constant for all experiments. The tabulated format of the results is shown in Table 2, which depicts the process parameter and output responses. The $S / N$ ratio indicates the higher value which signifying better machining performance such as for machining depth, 'higher-thebetter' and diametric cut, 'nominal is best'. Figure 5 and figure 6 show the experimental results and their microscopic images. The $S / N$ ratio is calculated from experimental data which provide measures of robustness to identify the control factors that reduce the variability of process. The $S / N$ ratio formula for machining depth higher the better is shown in Eq. 1 [22]:

$$
S / N=-10 \log \left(\frac{1}{n} \sum_{i=1}^{n} \frac{1}{y_{i}^{2}}\right)
$$

Tab. 1. Input Process parameters and their levels

\begin{tabular}{|c|c|c|c|c|c|}
\hline \multirow{2}{*}{ Factor } & \multirow{2}{*}{ Parameters } & \multirow{2}{*}{ Unit } & \multicolumn{3}{|c|}{ Levels } \\
\hline & & & 1 & 2 & 3 \\
\hline A & Voltage & $V$ & 70 & 80 & 90 \\
\hline $\mathrm{B}$ & Rotation & $\mathrm{r} / \mathrm{min}$ & 10 & 15 & 40 \\
\hline $\mathrm{C}$ & Electrolyte Concentration & $\%$ & 5 & 10 & 15 \\
\hline
\end{tabular}

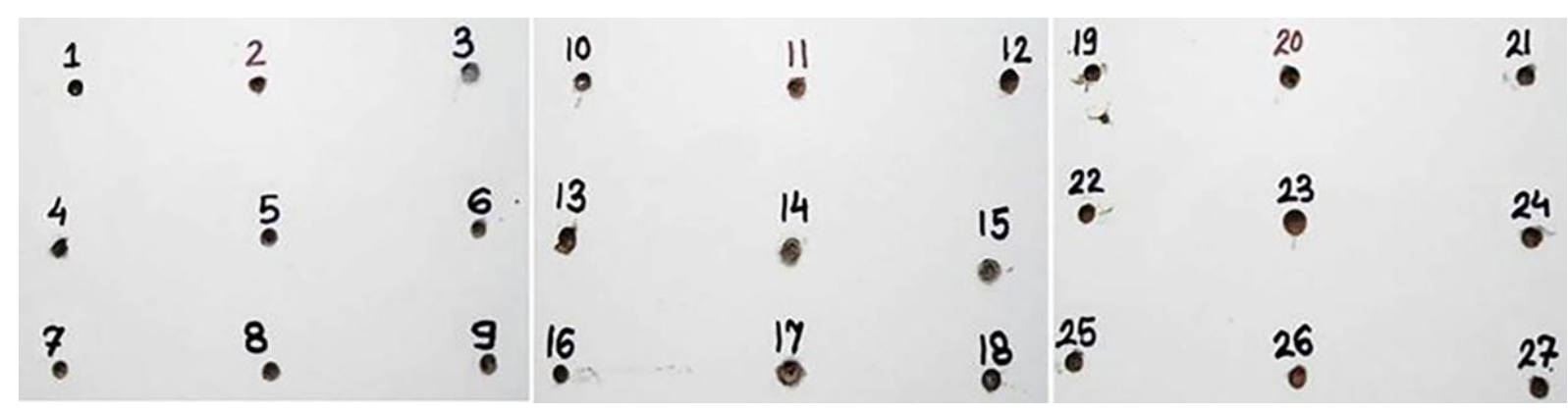

Fig. 5. Experimental results of ceramic material using ECDM 


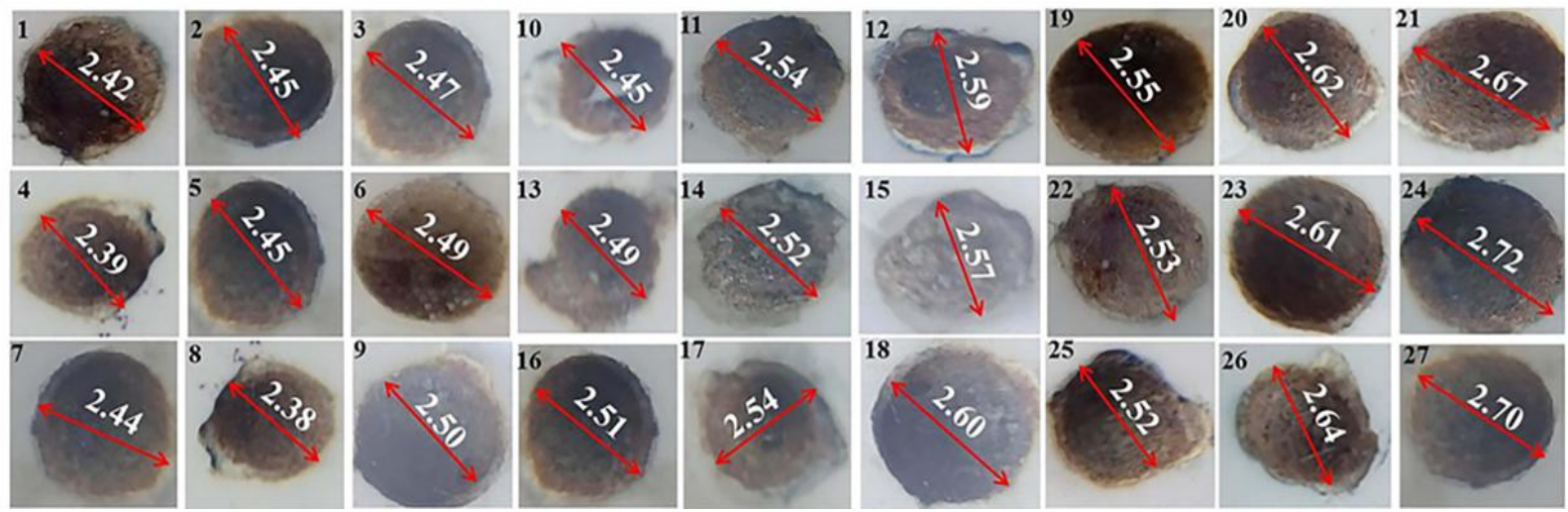

Fig. 6. Microscopic images of experimental results of ceramic material using ECDM

Tab. 2. Experimental results

\begin{tabular}{|c|c|c|c|c|c|}
\hline Run & Voltage & Rotation & Electrolyte Concentration & $\begin{array}{l}\text { Machining Depth } \\
(\mathrm{mm})\end{array}$ & Diametric cut (mm) \\
\hline 1 & 70 & 10 & 5 & 0.95 & 2.42 \\
\hline 2 & 70 & 10 & 10 & 1.01 & 2.45 \\
\hline 3 & 70 & 10 & 15 & 1.10 & 2.47 \\
\hline 4 & 70 & 25 & 5 & 0.99 & 2.39 \\
\hline 5 & 70 & 25 & 10 & 1.05 & 2.45 \\
\hline 6 & 70 & 25 & 15 & 1.15 & 2.49 \\
\hline 7 & 70 & 40 & 5 & 1.01 & 2.44 \\
\hline 8 & 70 & 40 & 10 & 1.10 & 2.38 \\
\hline 9 & 70 & 40 & 15 & 1.20 & 2.50 \\
\hline 10 & 80 & 10 & 5 & 1.15 & 2.45 \\
\hline 11 & 80 & 10 & 10 & 1.28 & 2.54 \\
\hline 12 & 80 & 10 & 15 & 1.37 & 2.59 \\
\hline 13 & 80 & 25 & 5 & 1.14 & 2.49 \\
\hline 14 & 80 & 25 & 10 & 1.30 & 2.52 \\
\hline 15 & 80 & 25 & 15 & 1.37 & 2.57 \\
\hline 16 & 80 & 40 & 5 & 1.17 & 2.51 \\
\hline 17 & 80 & 40 & 10 & 1.31 & 2.54 \\
\hline 18 & 80 & 40 & 15 & 1.41 & 2.60 \\
\hline 19 & 90 & 10 & 5 & 1.27 & 2.55 \\
\hline 20 & 90 & 10 & 10 & 1.37 & 2.62 \\
\hline 21 & 90 & 10 & 15 & 1.45 & 2.67 \\
\hline 22 & 90 & 25 & 5 & 1.30 & 2.53 \\
\hline 23 & 90 & 25 & 10 & 1.45 & 2.61 \\
\hline 24 & 90 & 25 & 15 & 1.52 & 2.72 \\
\hline 25 & 90 & 40 & 5 & 1.32 & 2.52 \\
\hline 26 & 90 & 40 & 10 & 1.47 & 2.64 \\
\hline 27 & 90 & 40 & 15 & 1.58 & 2.70 \\
\hline
\end{tabular}

\section{RESULTS AND DISCUSSION}

In the Taguchi technique, the least difference and the optimal parameters are attained by means of the $S / N$ ratio. The delta value represents the difference between the highest and lowest average assessment of $S / N$ ratio for each factor. The analysis was done using MINITAB 17 software.

\subsection{Effect on Machining depth}

The mean $S / N$ ratios plot denotes the influence of each parameter on machining depth. Fig. 7 shows the influence of the three different parameters viz. voltage, rotation and electrolyte concentration on the machining depth output response. The following figures demonstrate the linear increase in voltage resulting increase in machining depth; therefore it is the most significant parameter. From the experimental results, it is observed that the maximum machining depth increases with increasing applied voltage and electrolyte concentration, it may be due to generation of more electrical discharge from bottom of brass tool towards workpiece [24]. 


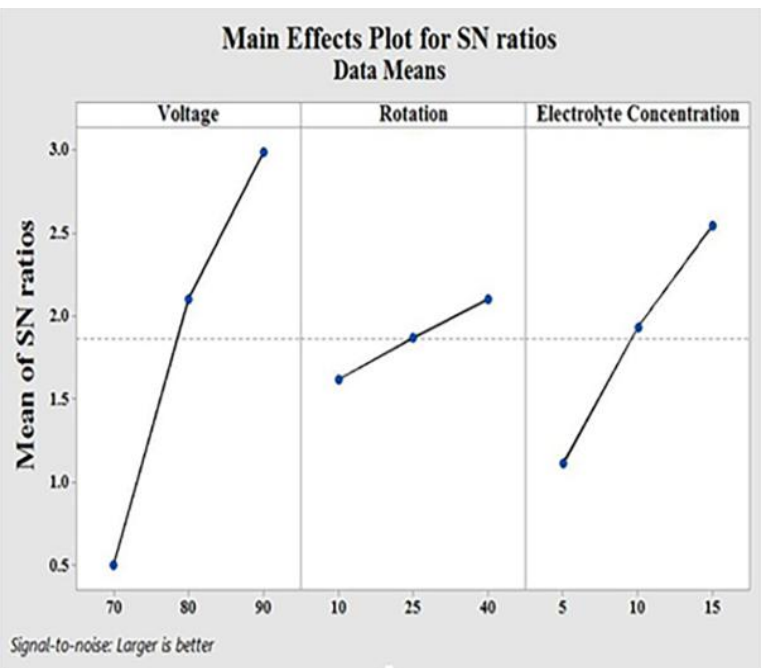

Fig. 7. Mean $S / N$ ratios plot for machining depth

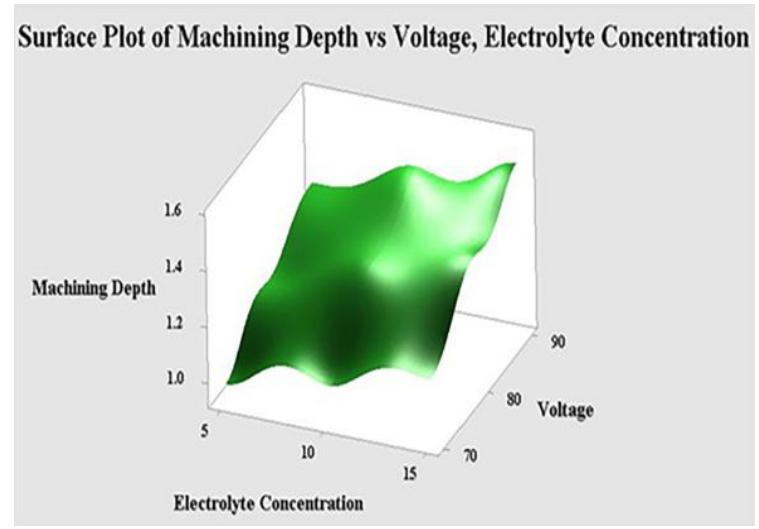

Fig. 8. Surface plot of machining depth vs. voltage, electrolyte concentration

Fig. 8 and Fig. 9 shows surface plot for machining depth. It represents the effect of voltage, rotation and electrolyte concentration on the machining depth.

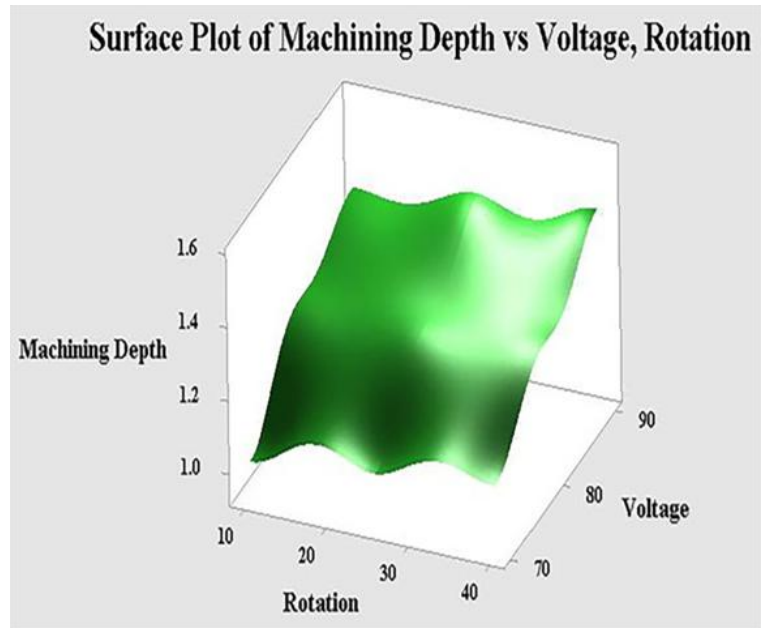

Fig. 9. Surface plot of machining depth vs. voltage, rotation

Table 3 shows ANOVA Table for machining depth. If $p$ value is smaller than 0.05 then the parameter is significant, here voltage, electrolyte concentration and rotation of tool electrode are the most significant parameters. Table 4 shows the average of each response characteristic for each level of each factor. This table specifies the ranks based on delta measurements and Minitab 17 allocates ranks based on delta values; rank 1 to the highest delta value, rank 2 to the second highest and, so on. The ranks designate the significance of each factor in the response. The ranks and delta values confirmed that the voltage has the greatest effect on machining depth followed by electrolyte concentration and rotation.

Tab. 3. ANOVA table for machining depth

\begin{tabular}{cccccc}
\hline Source & df & $\begin{array}{c}\text { Adj } \\
\text { SS }\end{array}$ & $\begin{array}{c}\text { Ad } \\
\text { MS }\end{array}$ & $\begin{array}{c}\text { F } \\
\text { Value }\end{array}$ & $\begin{array}{c}\text { P } \\
\text { Value }\end{array}$ \\
\hline Voltage & 2 & 0.5676 & 0.2838 & 455.84 & 0.00 \\
$\begin{array}{c}\text { Rotation } \\
\begin{array}{c}\text { Electrolyte } \\
\text { Concentration }\end{array}\end{array}$ & 2 & 0.0213 & 0.0106 & 17.16 & 0.07 \\
Error & 20 & 0.0124 & 0.0006 & & 0.00 \\
Total & 26 & 0.792 & & & \\
\hline S & & R-Sq. & R-sq.(adj.) & R-sq.(pred.) \\
0.0249518 & & $98.43 \%$ & $97.96 \%$ & $97.14 \%$
\end{tabular}

Tab. 4. Response table for signal to noise ratios of machined depth

\begin{tabular}{cccc}
\hline Level & Voltage & Rotation & $\begin{array}{c}\text { Electrolyte } \\
\text { Concentration }\end{array}$ \\
\hline 1 & 0.5019 & 1.6221 & 1.1151 \\
2 & 2.1042 & 1.8717 & 1.9350 \\
3 & 2.9902 & 2.1025 & 2.5462 \\
Delta & 2.4883 & 0.4804 & 1.4311 \\
\hline Rank & 1 & 3 & 2 \\
\hline
\end{tabular}

Eq. (2) shows mathematical model for the machining depth developed by using MINITAB 17 software:

\section{Machining.Depth $=-0.4204+0.017611 *$ Voltage + $0.00229 *$ Rotation $+0.02056 *$ Electrolye $\cdot$ Concentraton}

\subsection{Effect on Diametric cut}

The means of mean plot denotes the influence of each parameter on diametric cut. Figure 10 presents the influence of three different parameters viz. voltage, rotation and electrolyte concentration on the diametric cut output response. The following figures indicate the linear increase in voltage resulting increase in diametric cut therefore it is the most significant parameter. The voltage and electrolyte concentration are the most dominant factors for the diametric cut [25]. Eq. 3 shows a mathematical model for the 
diametric cut developed by using MINITAB 14 software:

Diametric $\cdot$ Cut $=1.7154+0.008722 *$ Voltage + $0.00025 *$ Rotation $+0.013 *$ Electrolyte $\cdot$ Concentration (3)

Fig. 11 and Fig. 12 shows the surface plot for diametric cut. It represents the effect of voltage, rotation and electrolyte concentration on the diametric cut.

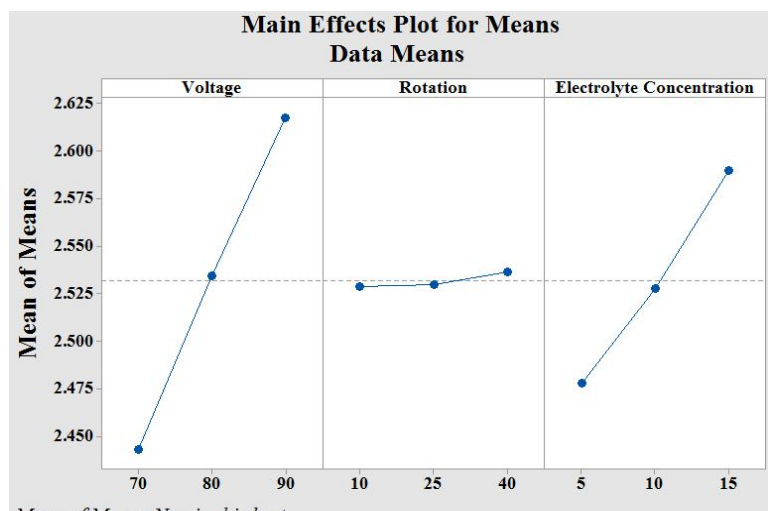

Fig. 10. Mean $\mathrm{S} / \mathrm{N}$ ratios plot for diametric cut

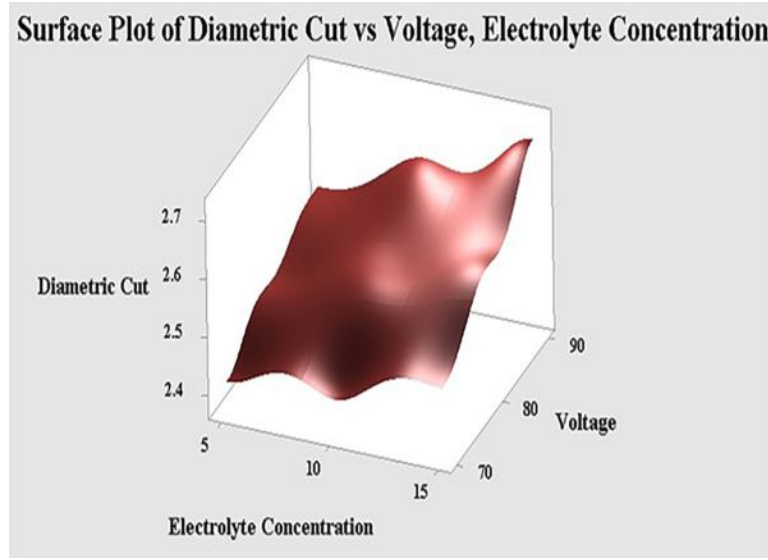

Fig. 11. Surface plot of diametric cut vs voltage, electrolyte concentration

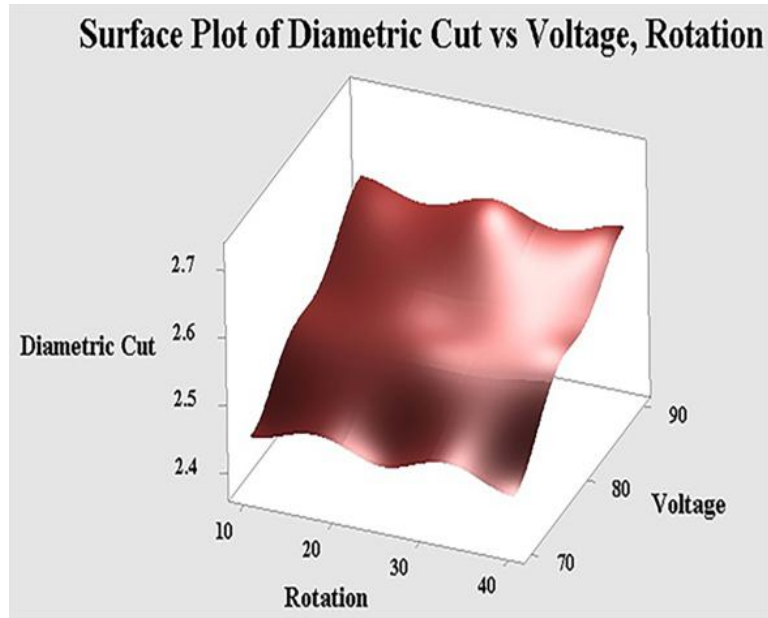

Fig. 12. Surface plot of diametric cut vs voltage, rotation
Table 5 shows ANOVA Table for diametric cut. If $p$ value is smaller than 0.05 , then the parameter is significant, here voltage and electrolyte concentration are the most significant parameters. The response Table 6 depicts the response for means of diametric cut for each level of each factor. The ranks and delta values confirmed that the voltage has greatest effect on diametric cut and is followed by electrolyte concentration and rotation.

Tab. 5. ANOVA table for diametric cut

\begin{tabular}{cccccc}
\hline Source & df & Adj SS & Adj MS & F-Value & P-Value \\
\hline Voltage & 2 & 0.1370 & 0.06851 & 78.92 & 0.00 \\
$\begin{array}{c}\text { Rotation } \\
\begin{array}{c}\text { Electrolyte } \\
\text { Concentration } \\
\text { Error }\end{array}\end{array}$ & 2 & 0.0003 & 0.00015 & 0.18 & 0.834 \\
Total & 20 & 0.0173 & 0.00086 & & 0.00 \\
\hline S & 26 & & & & \\
0.029 & R-Sq. & & R-sq.(adj.) & R-sq.(pred.) \\
\hline & $91.79 \%$ & $89.33 \%$ & $85.05 \%$ & \\
\hline
\end{tabular}

Tab. 6. Response table for means of diametric cut

\begin{tabular}{|c|c|c|c|}
\hline Level & Voltage & Rotation & $\begin{array}{l}\text { Electrolyte } \\
\text { Concentration }\end{array}$ \\
\hline 1 & 2.443 & 2.529 & 2.478 \\
\hline 2 & 2.534 & 2.530 & 2.528 \\
\hline 3 & 2.618 & 2. 537 & 2. 590 \\
\hline Delta & 0.174 & 0.008 & 0.112 \\
\hline Rank & 1 & 3 & 2 \\
\hline
\end{tabular}

\section{CONCLUSIONS}

The designed and manufactured electrochemical discharge machine setup was used for the present experimental investigation. In this work, two output responses i.e. machining depth and diametric cut were investigated by varying the three input process parameters on a conventional ceramic tile with Brass as a cathode electrode in an electrochemical discharge machine. The input parameters considered as voltage, rotation and electrolyte concentration. The experiments were conducted according to Taguchi $\mathrm{L}_{27}$ orthogonal array design. From the present study, it can be concluded that the voltage and electrolyte concentration are the most dominant factors for machining depth and diametric cut. However, rotation was the least significant factor for machining depth and diametric cut. The optimum parameters of the combination setting are Voltage $90 \mathrm{~V}$, Rotation $40 \mathrm{r} / \mathrm{min}$, and Electrolyte concentration $15 \%$ for the maximum machining depth and nominal diametric cut. 


\section{Nomenclature}

$\begin{array}{ll}\text { ECDM } & \text { - electrochemical discharge machining } \\ \text { S/N ratio } & \text { - signal to noise ratio } \\ \text { ANOVA } & \text { - analysis of variance } \\ r / \text { min } & \text { - rotation per minute } \\ d f & \text { - degree of freedom } \\ n & \text { - number of measurements } \\ y_{i} & \text { - measured values } \\ \text { Adj SS } & \text { - adjusted sum of squares } \\ \text { Adj MS } & \text { - adjusted mean squares } \\ \text { F-Value } & \text { - statistical value } \\ \text { P-Value } & \text { - probability value } \\ \text { DC voltage } & \text { - direct current voltage } \\ \text { mm } & \text { - millimeter } \\ S & \text { - response variable } \\ R \text {-Sq. } & \text { - percentage variation in response }\end{array}$

$R$-sq.(adj.) - adjusted percentage variation in response $R$-sq.(pred.) - predicted percentage variation in response

\section{References}

1. Pawar P., Ballav R., Kumar A. (2017). Machining Processes of Sapphire: An Overview, International Journal of Modern Manufacturing Technologies, Vol. 9, No.1, pp. 47-72.

2. Kurafuji H., Suda K. (1968). Electrical discharge drilling of glass, Annals of the CIRP, Vol. 16, pp. 415-419.

3. Pawar P., Ballav R., Kumar A. (2015). Measurement Analysis in Electrochemical Discharge Machining (ECDM) Process: A Literature Review, Journal of Chemistry and Chemical Engineering, Vol. 9, pp. 140144.

4. Bhattacharyya B., Doloi B., Sorkhel S. (1999). Experimental investigations into electrochemical discharge machining (ECDM) of non-conductive ceramic materials, Journal of Materials Processing Technology, Vol. 95, No. 1, pp. 145-154.

5. Pawar P., Ballav R., Kumar A. (2017). Recent status of Spark Assisted Chemical Engraving: A Review, Journal of Chemical and Pharmaceutical Sciences, Vol. 10, no. 2, pp. 1-6.

6. Pawar P., Ballav R., Kumar A. (2015). Revolutionary Developments in ECDM Process: An Overview, Materials Today: Proceedings, Vol. 2, No. 4-5, pp. 3188-3195.

7. Pawar P., Sinha S., Kumar A., Ballav R. (2014). Review on Research Trends in Electrochemical Discharge Machining, $4^{\text {th }}$ National Conference on Recent in Advances in Manufacturing (RAM-2014), SVNIT, Surat, India, pp. 132-136.

8. Wuthrich R., Fascio V. (2005). Machining of nonconducting materials using electrochemical discharge phenomenon-an overview, International Journal of Machine Tools and Manufacture, Vol. 45, No. 9, pp. 1095-1108.

9. Wuthrich R., Spaelter U., Wu Y., Bleuler H. (2006). A systematic characterization method for gravity-feed micro-hole drilling in glass with spark assisted chemical engraving (SACE), Journal of Micromechanics and Microengineering, Vol. 16, no. 9, pp. 1891-1896.

10. Jui S., Kamaraj A., Sundaram M. (2013). High aspect ratio micromachining of glass by electrochemical discharge machining (ECDM), Journal of Manufacturing Processes, Vol. 15, no. 4, pp. 460-466.

11. Sarkar B., Doloi B., Bhattacharyya B. (2006). Parametric analysis on electrochemical discharge machining of silicon nitride ceramics, International Journal of
Advanced Manufacturing Technology, Vol. 28, No. 9, pp 873-881.

12. Jain V., Choudhury S., Ramesh K. (2002). On the machining of alumina and glass, International Journal of Machine Tools and Manufacture, Vol. 42, No. 11, pp. 1269-1276.

13. Chak S., Rao P. (2008). The drilling of $\mathrm{Al}_{2} \mathrm{O}_{3}$ using a pulsed DC supply with a rotary abrasive electrode by the electrochemical discharge process, The International Journal of Advanced Manufacturing Technology, Vol. 39 , No. 7-8, 633-641.

14. Zheng Z., Su H., Huang F., Yan B. (2007). The tool geometrical shape and pulse-off time of pulse voltage effects in a Pyrex glass electrochemical discharge microdrilling process, Journal of Micromechanics and Microengineering, Vol. 17, No. 2, pp. 265-272.

15. Zhang Z., Huang L., Jiang Y., Liu G., Nie X., Lu H., Zhuang H. (2016). A Study to explore the properties of electrochemical discharge effect based on pulse power supply, The International Journal of Advanced Manufacturing Technology, Vol. 85, No. 9-12, pp. 2107-2114.

16. Doloi B., Bhattacharyya B., Sorkhel S. (1999). Electrochemical Discharge Machining of NonConducting Ceramics, Defence Science Journal, Vol. 49, No. 4, 331-338.

17. Harugade M.L., Kavade M.V., Hargude N.V. (2013). Effect of electrolyte solution on material removal rate in electrochemical discharge machining, IOSR J. Mech Civil Eng., pp.1-8.

18. Pawar P., Ballav R., Kumar, A. (2018). FEM Analysis of Different Materials Based on Explicit Dynamics ANSYS in Electrochemical Discharge Machine. In Simulations for Design and Manufacturing, Springer, Singapore, pp. 231-258.

19. Goud, M., Sharma, A.K. (2017). A three-dimensional finite element simulation approach to analyze material removal in electrochemical discharge machining, Proceedings of the Institution of Mechanical Engineers, Part C: Journal of Mechanical Engineering Science, Vol. 231, No. 13, pp.2417-2428.

20. Pawar P., Ballav R., A. Kumar. (2017). Material removal rate and tool wear rate analysis by ECDM drilling of a mosaic ceramic material, International Journal of Modern Manufacturing Technologies, Vol. 9, No. 2, pp. 51-58.

21. Pawar P., Ballav, R., Kumar, A. (2018). Material Removal Analysis of Soda-lime glass by using Electrochemical Discharge Drilling Process, Asian Journal of Chemistry, Vol. 30, No. 4, pp. 879-882.

22. Paul L., Hiremath S. (2014). Evaluation of process parameters of ECDM using Grey Relational Analysis, Procedia Materials Science, Vol. 5, pp. 2273-2282.

23. Pawar P., Kumar A., Ballav R. (2018). Development And Manufacturing of Arduino Based Electrochemical Discharge Machine, Journal of Machine Engineering, Vol. 18, No. 1, pp. 45-60.

24. Mallick B., Sarkar B., Doloi B., Bhattacharyya B. (2014) Multi criteria optimization of Electrochemical Discharge Micromachining process during micro-channel generation on glass, Applied Mechanics and Materials, Vol. 592-594, pp. 525-529.

25. Chak, S., Rao P. (2007). Trepanning of $\mathrm{Al}_{2} \mathrm{O}_{3}$ by electrochemical discharge machining (ECDM) process using abrasive electrode with pulsed DC supply, International Journal of Machine Tools and Manufacture, Vol. 47, No. 14, pp. 2061-2070. 


\section{Biographical notes}

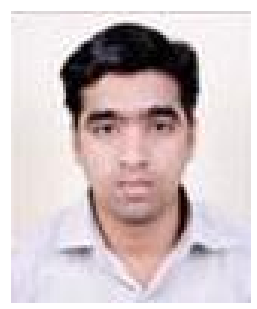

Pravin Pawar has pursuing Ph.D. in De-partment of Manufacturing Engineering, National Institute of Technology, Jamshedpur, India. He has published more than 10 papers in referred journals and conferences.

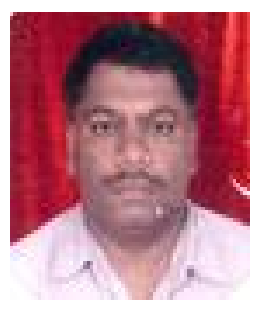

Amaresh Kumar has Professor in Department of Manufacturing Engineering, National Institute of Technology, Jamshedpur, India. He has published more than 25 papers in referred journals and conferences

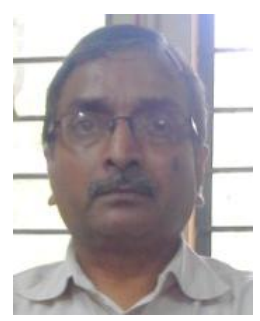

Raj Ballav has Associate Professor in Department of Manufacturing Engineering, the National Institute of Technology, Jamshedpur, India. He has published more than 15 papers in referred journals and conferences. 